\title{
Intergranular Stress Corrosion Cracking of $\alpha$-Brass in an Ammoniacal Non-tarnishing Solution
}

\author{
Toshihei Misawa* and Hiroyoshi Murakami** \\ Department of Metallurgical Engineering, Muroran Institute of Technology*
}

\begin{abstract}
Stress-corrosion tests of $\mathrm{Cu}-30 \% \mathrm{Zn}$ alloy under a constant strain rate were conducted in Mattsson's type solution of both non-tarnishing( $\mathrm{pH} \mathrm{4.3)}$ and tarnishing( $\mathrm{pH} 7.0)$ conditions, in order to examine the relation between the mode of cracking in tarnishing and non-tarnishing solutions. Fractographic examination showed that intergranular cracking predominated in a non-tarnishing solution of $\mathrm{pH} 4.3$, where it has been reported that $\mathrm{U}$-bend specimen failured indicates the nature of transgranular cracks. It is thought that a single distinction of the cracking form by tarnishing or non-tarnishing conditions is not justified, due to the observed evidence of intergranular stress-corrosion cracking occured in both conditions.
\end{abstract}

\section{Introduction}

It is well known that in the $\alpha$-brass-ammoniacal solutions the mode of stress corrosion cracking, intergranular or transgranular, depends mainly on $\mathrm{pH}$ valve of the solution as originally reported by Mattsson. ${ }^{11}$ Mattsson's work using U-bend specimens indicated that path of cracking was intergranular in neutral tarnishing solutions, producing a characteristic blackish tarnish film of $\mathrm{Cu}_{2} \mathrm{O}$ and transgranular in non-tarnishing solutions of either side of the neutral tarnishing zone of $\mathrm{pH}$ 6.3-7.3. Such distinction of fracture form has been supported by other workers, ${ }^{2,3)}$ and the role of tarnish film has been emphasized in the mechanism of intergranular cracking for tarnishing condition, as the tarnish film rupture mechanism ${ }^{4)}$ or film theory. ${ }^{51}$

There are several published works ${ }^{3,61}$ showing that transgranular cracking occurred in nontarnishing ammoniacal solutions of alkaline $\mathrm{pH}$, where metal undergoes active anode dissolution in the absence of tarnish film. However, only little work has been done on stress corrosion cracking in non-tarnishing solutions of lower $\mathrm{pH}$ since Mattsson's work. In this note, fracture surface obtained by constant strain rate test in a nontarnishing solution of $\mathrm{pH} 4.3$ showed that intergranular cracking predominated, as well as cracking mode in tarnishing condition.

\section{Experimental}

Cylindrical tensile specimens of $30 \mathrm{~mm}$ gage

* 27-1, Mizumoto-cho, Muroran 050, Japan

** Now at Graduate School, Hokkaido University, Sapporo 060, Japan length and a reduced cross-section of $6 \mathrm{~mm}$ diameter were prepared from the cold-drawn bar of $\alpha$-brass $(70.10 \% \mathrm{Cu}-\mathrm{Zn})$. After machining, all specimens wrapped by thin-foil of the same composition were annealed at $500^{\circ} \mathrm{C}$ for 5 hours in vacuum. The specimen after this heat treatment had a tensile strength of $33.2 \mathrm{~kg} / \mathrm{mm}^{2}$ and the grain size was approximately $50 \mu$. Stress-corrosion tests were carried out using an Instron tensile machine with an initial strain rate of $2.8 \times 10^{-4}$ $\mathrm{sec}^{-1}$. The test solution used was Mattsson's type solution consisting of copper sulphate and ammonium sulphate aqueous solution $\left(0.04 \mathrm{M} \mathrm{CuSO}_{4}\right.$. $\left.5 \mathrm{H}_{2} \mathrm{O}+0.75 \mathrm{M}\left(\mathrm{NH}_{4}\right)_{2} \mathrm{SO}_{4}, \mathrm{pH} 4.3\right)$. This test solution of pH 4.3 was considered to be "non-tarnishing," because surface of tensile specimens retained a metallic lustre of $\alpha$-brass throughout the test over 8 hours. The tarnishing solution of $\mathrm{pH} 7.0$ was prepared by addition of $\mathrm{NH}_{4} \mathrm{OH}$ solution and the surface of $\alpha$-brass was rapidly (in a matter of minutes) covered with a black tarnish film.

Fracture surfaces were examined in the scanning electron microscope with no treatment after removal from the environment other than washing and drying.

\section{Results and Discussion}

Stress-strain curves obtained for tensile specimens in ammoniacal solutions showed that the strain to failure was smaller in a tarnishing solution of $\mathrm{pH} 7.0$ than in a non-tarnishing solution of $\mathrm{pH}$ 4.3.

The fracture surfaces grown in a solution of pH 4.3, where U-bend specimens by Mattsson ${ }^{11}$ indicated the nature of transgranular cracks, 


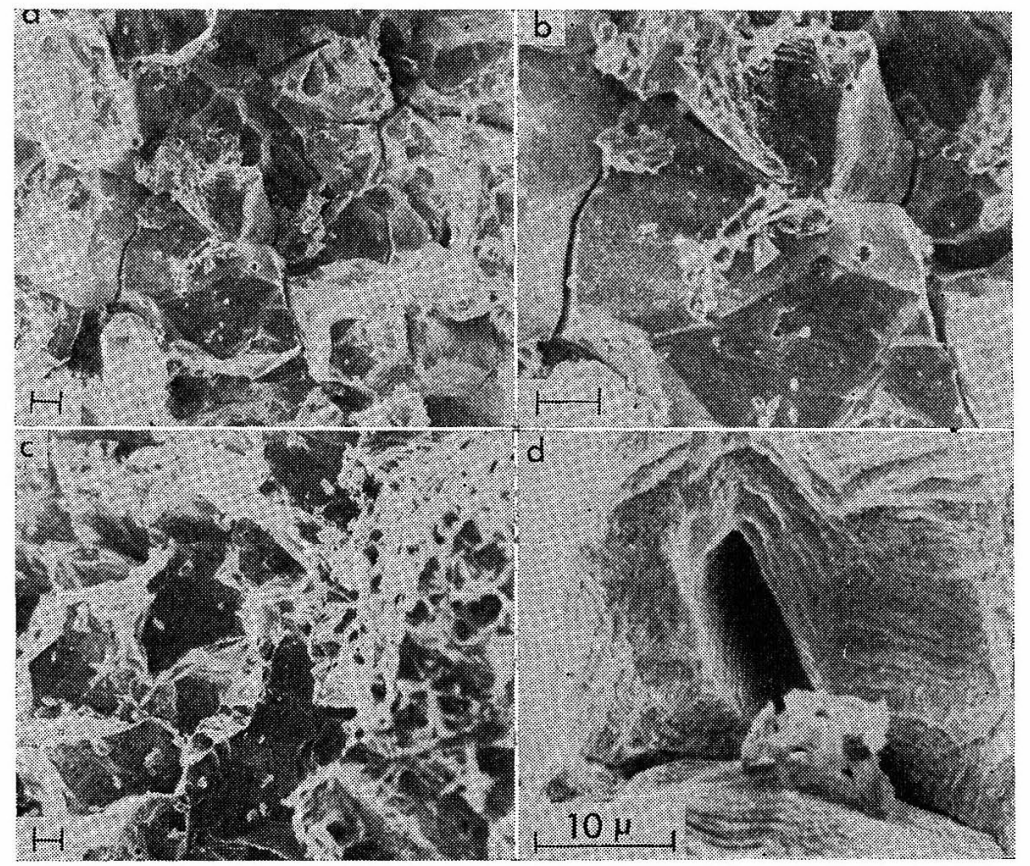

Fig. 1. Fracture surfaces showing intergranular fracture, grown in a non-tarnishing solution of pH 4.3 at $\dot{\varepsilon}=2.8 \times 10^{-4} \mathrm{sec}^{-1}$.

(a) An example of intergranular fracture. (b) Enlarged view of intergranular surfaces in (a), showing slip lines. (c) Transition from intergranular cracking (left hand) to a dimpled ductile appearance of final mechanical failure (right hand). (d) Cracks at grain-boundary triple point and striations on grain surfaces.

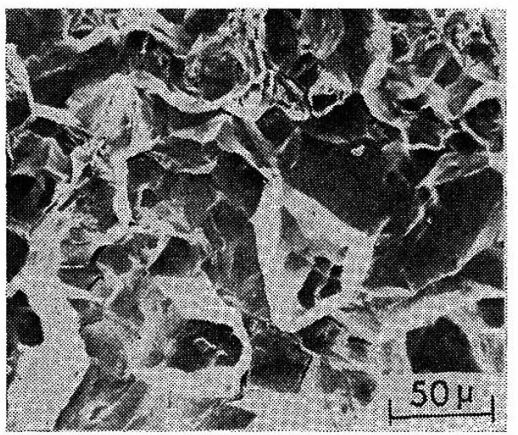

Fig. 2. An example of intergranular fracture, grown in a tarnishing solution of $\mathrm{pH} 7.0$ at $\dot{\varepsilon}=2.8 \times 10^{-4} \mathrm{sec}^{-1}$.

Note the fresh fracture surface was yellow, not black.

showed a predominantly intergranular mode of cracking (Fig. 1). As shown in Figs. 1(a) and 1(c), intergranular mode of cracking occupied almost area failured by stress-corrosion and a dimpled ductile region was limited to the final mechanically fractured core. Figure 1(b) shows an enlarged view of intergranular surfaces with high magnification, and the slip lines can be seen on the grain surfaces. These slip traces have been observed on intergranular surfaces of stress corrosion cracking of $\alpha$-brass in ammoniacal solutions ${ }^{6-91}$ and would be a general characteristic of intergranular failures of metals accompanied by significant amounts of plastic strain in a corrosive euvironment. Secondary cracks were frequently observed at grainboundary triple points on intergranular fracture surfaces. Figure 1(d) shows microcracks branching off the main fracture surface at grain-boundary triple point, and numerous fine striations which probably produced by preferential corrosion at the slip traces appeared on surfaces of grains.

For the purpose of comparison, a tensile specimen was broken in a tarnishing solution of $\mathrm{pH}$ 7.0. The fractographs obtained in tarnishing region showed a predominantly intergranular cracking (Fig. 2), as well known. ${ }^{1-9)}$ It should be noted that the stress-corrosion fracture surface of $\alpha$-brass, after failured in $\mathrm{pH} 7.0$ tarnishing solution, was yellow and was not covered by a black "tarnish" film, as reported by Tromans et al. ${ }^{10)}$ and other workers. ${ }^{7,11)}$

The difference of the crack mode between U-bend specimen by constant deflection method and the 
tensile specimen applied constant strain rate suggests that the strain rate, or the formation rate of the slip steps is one of the important factors in the mechanism of stress corrosion cracking of $\alpha$ brass in non-tarnishing solution of low pH. Evidence of the fractographic observation in this work is that intergranular cracking is the dominant form of failure under the constant strain rate in a nontarnishing condition( $\mathrm{pH} 4.3)$, as well as cracking mode in a tarnishing condition( $\mathrm{pH} 7.0$ ). Recently, Sparkes and Scully ${ }^{9)}$ measured the stress-corrosion crack velocity of $\alpha$-brass specimens loaded in a cantilever beam apparatus as a function of $\mathrm{pH}$ of ammoniacal solutions. They have observed a high proportion of intergranular cracking on the fracture surfaces grown at $\mathrm{pH}$ values 4.6-12.5. The authors $^{12)}$ have found that the corrosion fatigue cracks of $\alpha$-brass in ammoniacal solution were predominantly intergranular in nature in either nontarnishing and tarnishing conditions between $\mathrm{pH} 4.3$ and 7.5, and the mixture of intergranular crack path and a high proportion of transgranular cracking in non-tarnishing solution of $\mathrm{pH}$ 8.0-9.8.

It is concluded that a single distinction of the cracking form by tarnishing or non-tarnishing conditions is not justified, on the basis of fractographic evidence. Further work is required to elucidate a general features of intergranular stress-corrosion cracking in this system.

\section{Acknowledgements}

The authors wish to express their thanks to Prof.
Hideo Sugawara and Mr. Hidehiko Kamide for their valuable discussions. Thanks are also due to the Sumitomo Light Metal Industries Ltd. for kindly supplying the materials.

(Received March 25, 1976)

\section{References}

1) E. Mattsson: Electrochim. Acta, 3, 279 (1961).

2) E. N. Pugh: "The Theory of Stress Corrosion Cracking in Alloys," Ed. by J. C. Scully, p. 418, NATO, Brussels (1971).

3) E. N. Pugh, J. V. Craig \& A. J. Sedriks: Proc. of Conf. on Fundamental Aspects of Stress Corrosion Cracking, Eds. by R. W. Staehle et al., p. 118, NACE, Houston (1969).

4) A. J. McEvily \& A. P. Bond: J. Electrochem. Soc., 112, 131 (1965).

5) M. Takano \& S. Shimodaira: Corros. Sci., 8, 55 (1968).

6) M. Takano: Corros. Sci., 11, 813 (1971).

7) S. S. Birley \& D. Tromans: Corrosion, 27, 297 (1971).

8) D. J. Lees: Corros. Sci., 12, 811 (1972).

9) G. M. Sparkes \& J. C. Scully: Corros. Sci., 14, 619 (1974).

10) D. Tromans, N. A. Dowds \& J. Leja: Proc. of Conf. on Fundamental Aspects of Stress Corrosion Cracking, Eds. by R. W. Staehle et al., p. 154, NACE, Houston (1969).

11) R.P.M. Procter \& G.N. Stevens: Corros. Sci., 15, 349 (1975).

12) T. Misawa, K. Tsuji \& H. Sugawara: to be published in J. Japan Inst. Metals. 